\title{
First Laparoscopic Appendicectomy in a Tertiary Health Facility in Calabar, Nigeria- A case report: Prospects and Challenges.
}

\author{
O Engim ${ }^{1}$, Tedentekhe $^{2}$, Q Kalu ${ }^{3}$, Mekong4, Ponwuadika $^{5}$, B Chukwu $^{6}$, \\ A Uetiuma $^{7}$, Aessiet $^{8}$, Rndoma-Egba $^{9}$ \\ ${ }^{1,4,6-9}$ Department of Surgery, University of Calabarand University of CalabarTeaching Hospital, Calabar, Cross \\ River State, Nigeria. \\ ${ }^{2,3 \& 5}$ Department of Anesthesia ,University of Calabar and University of CalabarTeachingHospital,Calabar, \\ Cross River State, Nigeria.
}

\begin{abstract}
Laparoscopic surgery has been in practice in the developed worldfor several decades now. However, in Nigeria, like in most developing countries, laparoscopic surgery is still at an infancy stage, partly because of lack of trained personnel and also due to lack of facilities. Laparoscopic appendicectomy has been shown in several studies to shorten the hospital stay, reduce morbidity and encourage early return to work for patients who were treated this way compared to open appendicectomy. Also postoperative surgical site infection is almost non-existent with laparoscopic appendicectomy compared to open appendicectomy. The aim of this paper is to present our firstexperience with laparoscopicappendicectomy in this centre and to highlight the challenges/prospects of this method of treatment in our setting. This was the first therapeutic laparoscopic procedure performed in this tertiary health facility in Calabar, south-south, Nigeria.This is a case presentation of a 24 year old lady diagnosed of acute appendicitis and had laparoscopic appendicectomy done in ourcentre. She was discharged on the second post operative day in satisfactory condition.
\end{abstract}

Keywords:First, Laparoscopic appendicectomy, Calabar,Nigeria.

\section{I.Introduction}

The development of laparoscopic surgery in Nigeria is rather slow compared to the Western world. The first record of laparoscopy was done by Kelling, over 100 years ago when he inspected the abdominal cavity of a dog using a cystoscope $e^{1,2}$.In the early years, laparoscopy was mainly diagnostic but with technological advancement andimproved instrumentation over the years, therapeutic procedures gradually took the centre stage ${ }^{1-5}$.In 1981, Semm, from the UniversitatsFrauenklinik, Kiel, Germany, performed the first Laparoscopic Appendicectomy $^{2}$. Since then, several studies have been done to compare laparoscopic appendicectomyandopenappendicectomy ${ }^{1,2,5,9}$. Most of these studies clearly found that laparoscopic appendicectomy gave a better cosmesis, reduced postoperative morbidity, reduced hospital stay, encouraged early return to work and had a lower incidence of post-operative surgical site infection when compared with open appendicectomy ${ }^{1,2,5,9}$.

The drawbacks of laparoscopic appendicectomyinclude the high cost of specialized equipment and the need for highly skilled expertise which are not readily available in most centres in Nigeria and other developing countries.Also,generalanaesthesia is required for laparoscopic appendicectomy with its attendant potential complications while regional anaesthesia often suffice for open appendicectomy ${ }^{2-4}$. The aim of our case presentation is to share our first experience with laparoscopic appendicectomy in the University of Calabar Teaching Hospital, Nigeria.

\section{Case presentation}

\section{Materials and Methods}

A 24-year old female was admitted throughthe emergency unit of the University of Calabar Teaching Hospital on account of right-sided lower abdominal pain, fever and vomiting, all of two days duration. An abdominal ultrasound scan done suggested acute appendicitis but excluded cyesis and pelvic inflammatory disease. A diagnosis of acute appendicitis was made after due assessment and she was scheduled for laparoscopic appendicectomy. Relevant pre-operative baseline investigations were done and were satisfactory. An informed consent was obtained for laparoscopic surgery before the laparoscopic appendicectomy was done.

The surgery was done under general anaesthesiausing the standard three port technique $(11 \mathrm{~mm}$ umbilical port for the camera and two $5.5 \mathrm{~mm}$ working ports in the left iliac fossa and suprapubic regions). Carbon dioxide pneumoperitoneum was used for the procedure. Intraoperative findings were an inflamed appendix with fibrous adhesions plastering it to the anterior abdominal wall.Adhesiolysis with appendicectomy was done, haemostasis on the mesentry was secured with diathermy and a Rhoeder's knot(x2) used to secure the 
base of the appendix. Umbilical fascia was closed with vicryl-0 and subcuticular closure of skin incisions done with fine absorbable suture. Surgery was successful and lasted 75 minutes. Patient was discharged on the second postoperative day in good condition and she did not have any complication after discharge. Figure 1 shows the appendicectomy specimen with part of the Rhoeder's knot while figure 2 shows the postop picture of the patient with the port sites just before discharge from the hospital.

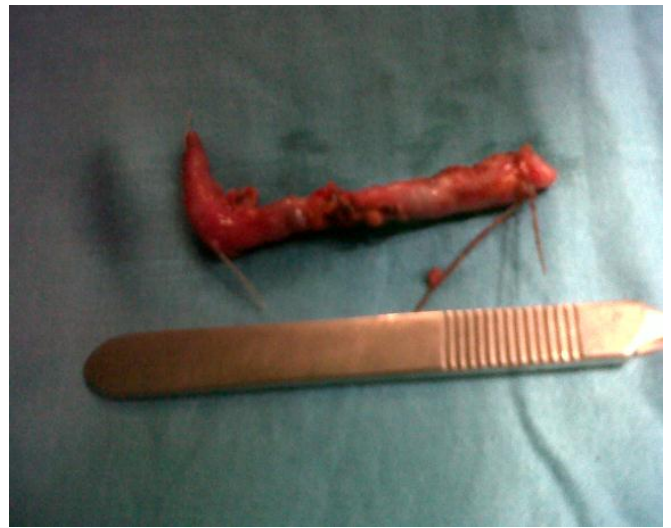

Figure 1: Shows the appendix specimen with remnants of the chromic catgut used for the Rhoeder'sknots .

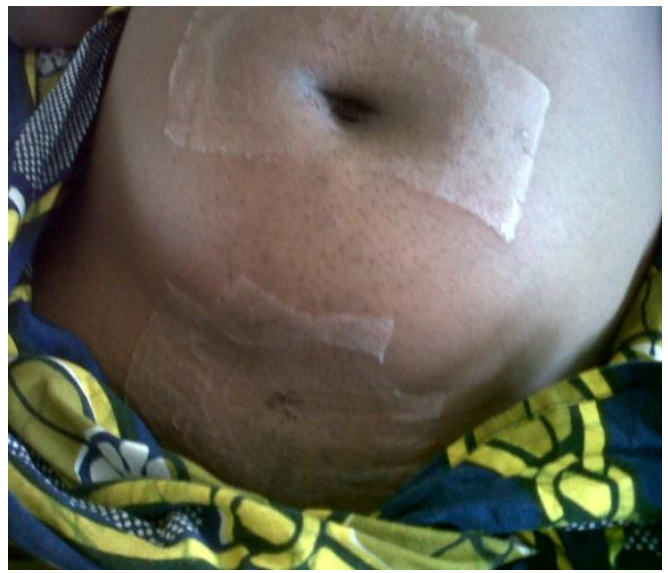

Figure 2: Shows the port sites just before discharge from the hospital. The temporary elastoplast impression on the skin is also noted.

\section{Discussion}

The development of laparoscopic surgery in Nigeria though slow, is gradually experiencing a leap as more surgeons are becoming trained in this emerging subspecialty in Nigeria ${ }^{5}$. Laparoscopic appendicectomy is not an innocuous procedure as it can be fraught with dangers if ventured into by an untrained surgeon in the field of laparoscopic surgery ${ }^{1,5-9}$. Though many studies report a marginal advantage of laparoscopic appendicectomy over the open technique ${ }^{6-9}$, others opine that it has clear advantages over the open technique ${ }^{1-2}$. Whereas some argue that Laparoscopic appendicectomy (LA) takes more time to perform compared to the open technique, others are of the opinion that once the learning curve is over, the timespent in carrying out LA is similar to that for open appendicectomy ${ }^{2,6-10}$. Though the period of aneasthesia for LA is often longer than that for open surgery many surgeonsfavour the use of LA because in their experience,these patients had a better quality of life in the immediate post-operative period and thereafter compared to those with open surgery ${ }^{2,10}$.Our index patient gives credence to this assertion because she experienced much less pain compared with those who had been having open appendicectomy and was able to ambulate with minimal discomfort right from the first post-operative day. Also, the cosmetic outcome was better (Figure 2), her post-operative morbidity was minimal compared to the open technique and she also had early discharge from the hospital as well as return to normal activity. These were all desirable advantages of LA noted in this case.Although, documentation in some large series in the literature indicate that the incidence of postoperative wound infection is much less with LA compared to the open method, this conclusion cannot be drawn here since only one case is being reported even though she did not have any port site infection. Furthermore,laparoscopy offers an additional advantage in ladies as this can clearly resolve diagnostic dilemma since some gynaecological conditions can simulate acute appendicitis in females ${ }^{3,4}$. 
The outcome of our first experience with laparoscopic appendicectomy in our facility is encouraging as our index patient benefitted from some of the advantages of LA, despite some of the drawbacks of the procedure as noted in the literature ${ }^{1-2,5-9}$.It is our opinion that Laparoscopic appendicectomyoffers a better quality of life, early postoperative recovery and an early return to workthan open appendicectomy and should be encouraged even in our setting. The high cost of equipment needed for laparoscopic surgery is a major limitation in our environment because this often translates to a higher cost of the procedure and many patients may not be able to afford it.

\section{Conclusion}

Laparoscopic appendicectomy is safe and has the potential of reducing the post-operative morbidity of patients thus, encouraging early return to work. This has economic benefits not only for the patient, but also for the society at large. The better cosmesis it offers is also a desirable result for many patients. Its practice should be encouraged.

\section{References}

[1]. C N Ekwunife, G U Chianakwana,S N Anyanwu,CEmegoakor. Pioneering Laparoscopic Surgery in South-Eastern Nigeria: A twocentre general surgery experience.Niger J Basic ClinSci9,2012,75-8.

[2]. MGBhat. Laparoscopic Appendicectomy, in A Kriplani, P Bhatia,APrasad,DGovil,HPGarg(Eds),Comprehensive Laparoscopic Surgery (SagarPrinters,Near South Extension-I,New Delhi, 2007)135-139.

[3]. P R O'Connell. The vermiform appendix in NSWilliams,CJKBulstrode,P R O'Connell (Eds), Bailey and Love's Short Practice of Surgery, 25 (London: Edward Arnold 2008)1204-1218.

[4]. J N Clegg-Lamptey, JK Ladipo. Minimally Invasive Surgery in EABadoe, EQArchampong,JTda-Rocha-Afodu(Eds). Principles and Practice of Surgery -Including Pathology in the Tropics, 4( Accra: Assemblies of God Literature Centre Ltd. 2009)1397-13108.

[5]. BO Ismaila,MAMisauno. Laparoscopic general surgery-the journey so far.Nigerian Journal of Medicine ,9(2),2012,75-78.

[6]. LEnochsson,AHellberg,CRudberg,GFenyo,TGudbjartson,EKullman,IRingqvist,SSorensen,JWenner. SurgEndosc, 15(4),2001, 38792

[7]. X Li, J Zhang, L Sang, W Zhang, Z Chu, X Li,YLiu . Laparoscopic versus conventional appendectomy - a meta-analysis of randomized controlled trials .BMC Gastroenterology,10,2010, 129

[8]. NKatkhounda,R J Mason,STowfigh,AGevorgyan,REssani. Laparoscopic versus open appendectomy: A prospective Randomised double blind study. Ann Surgery,242(3),2005, 439-450.

[9]. STanaka, DKubota, SHLee, KOba, MMatsuyama. Effectiveness of laparoscopic approach for acute appendicitis. Osaka City Med J,53(1) 2007,1-8.

[10]. D Costa-Navarro, M Jiménez-Fuertes and AIllán-RiquelmeLaparoscopic appendectomy: quality care and cost-effectiveness for today's economy. World Journal of Emergency Surgery ,8,2013,45 